\title{
Secondary progression and innate immunity in NMO
}

\author{
A possible link to alemtuzumab therapy?
}

Kazuo Fujihara, MD

Ichiro Nakashima, MD

Correspondence to Dr. Fujihara:

fujikazu@med.tohoku.ac.jp

Neurol Neuroimmunol Neuroinflammation 2014;1:e38; doi: 10.1212/ NXI.0000000000000038

\section{See article}

Multiple sclerosis (MS) eventually evolves from a relapsing-remitting to a progressive phase in most cases. Progressive MS is characterized by inflammationtriggered neurodegeneration, microglial activation, restored integrity of blood-brain barrier (BBB), prominent meningeal infiltrates of $\mathrm{B}$ and $\mathrm{T}$ lymphocytes, and cortical demyelination. ${ }^{1,2}$ Available disease-modifying drugs for MS cannot reverse the chronic progression.

Meanwhile, disability of neuromyelitis optica spectrum disorders (NMOSD) is essentially attackrelated. In a report, only $2(2 \%)$ of 96 patients with definite NMO converted to a secondary progressive course (myelopathy) during a median follow-up of 6.1 years, contrary to the estimate of 21 converted cases based on MS data. ${ }^{3}$ In fact, progressive neurologic deterioration (over months to years) unrelated to attacks is a clinical "red flag" in the newly proposed diagnostic criteria for NMOSD. ${ }^{4}$ A target antigen of NMOSD-specific autoantibody is aquaporin- 4 (AQP4), a dominant water channel richly expressed in astrocytic end feet in the CNS, and experimental studies have convincingly demonstrated the pathogenicity of AQP4-immunoglobulin (Ig) G. AQP4-IgG-positive NMOSD is predominantly astrocytopathic in pathologic classification, and, unlike MS, demyelination in this type of NMOSD appears to be a secondary phenomenon..$^{5}$ Although there has been no previous neuropathologic report focusing on secondary progressive NMOSD, it is interesting to examine whether the secondary progressive phase in NMOSD is distinct from that in MS.

In this issue of Neurology ${ }^{\circledR}$ Neuroimmunology \& Neuroinflammation, Gelfand et al. ${ }^{6}$ reported an interesting autopsied case of AQP4-IgG-positive NMOSD that developed progressive neurologic deficits and slowly expanding, nonenhancing brain lesions after alemtuzumab therapy. This 61-year-old white woman had highly active AQP4-IgG-positive NMOSD (10 relapses in 4 years, wheelchair dependent due to severe paraparesis) refractory to first-line immunosuppressive drugs for $\mathrm{NMOSD}^{7}$ such as corticosteroids, mycophenolate mofetil, and rituximab. After alemtuzumab, a highly potent drug for MS targeting CD52, was administered in the same regimen as MS (with a second course of infusions given 15 months after initial therapy), there was no relapse or gadolinium-enhanced MRI lesions, but the patient developed insidiously progressive and intractable nausea and vomiting that led to severe weight loss and progressive bilateral visual loss. In accordance with these progressive neurologic symptoms, serial brain MRI revealed expanding T2/fluid-attenuated inversion recovery (FLAIR) hyperintense lesions without enhancement in the bilateral cerebral white matter and brainstem. The distribution of those brain MRI lesions was relatively symmetrical, which is uncommon in NMOSD. Despite enteral feeding, the patient did not show clinical improvement and later died at home.

Macroscopic observation revealed severe destruction of spinal cord tissues, optic nerve discoloration, and a number of gelatinous demyelinating lesions in the cerebral white matter and cerebello-brainstem regions including the medullary area postrema, whose lesions in NMOSD often cause intractable hiccups, nausea, and vomiting. Some cavitary lesions with gliosis in the periphery were also seen in the periventricular regions and the callosal genu. These brain lesions corresponded to gradually expanding T2/FLAIR hyperintense lesions without contrast enhancement detected by MRI. Microscopic examination demonstrated demyelinating lesions ranging from acute to chronic stage in the regions mentioned above, and it is interesting that all of these lesions in the brain, cervical cord, and optic nerve were characterized by severe loss of luxol fast blue stain for myelin and infiltration of numerous CD68-positive macrophages. On the other hand, there were few CD4-positive T lymphocytes or CD20-positive B lymphocytes in those lesions. Progressive multifocal leukoencephalopathy, a possible alternative diagnosis, was ruled out.

\footnotetext{
From the Departments of Multiple Sclerosis Therapeutics (K.F.) and Neurology (K.F., I.N.), Tohoku University Graduate School of Medicine, Sendai, Japan.

Go to Neurology.org/nn for full disclosures. Funding information and disclosures deemed relevant by the authors, if any, are provided at the end of the editorial. The Article Processing Charge for this editorial was waived at the discretion of the Editor.

This is an open access article distributed under the terms of the Creative Commons Attribution-Noncommercial No Derivative 3.0 License, which permits downloading and sharing the work provided it is properly cited. The work cannot be changed in any way or used commercially.
} 
Alemtuzumab binds to CD52, a surface glycoprotein on $\mathrm{T}$ and $\mathrm{B}$ lymphocytes, and deletes immune cells to induce long-lasting suppression of adaptive immunity. Although alemtuzumab is highly effective in relapsing-remitting MS, it fails to inhibit chronic progression. ${ }^{8}$ Based on the present case and the drug data, Gelfand et al. speculated that active innate immunity, as evidenced by massive infiltration of CD68-positive macrophages (some of which may be microglia) in the absence of disrupted BBB, might be associated with the progressive phase in this patient as a result of abrogation of adaptive immunity by alemtuzumab. They also suspected that this possible innate immunity-driven pathology might be relevant to secondary progression in MS as well as NMOSD. In addition, since alemtuzumab can induce such autoimmunities as idiopathic thrombocytopenic purpura, Goodpasture syndrome, and thyroid disease, it may possibly exacerbate NMOSD by enhancing production of AQP4-IgG or myelin oligodendrocyte glycoprotein-IgG.

While relapsing-remitting MS is mainly operated by antigen-specific adaptive immunity, chronic inflammation in secondary progressive MS activates dendritic cells in the blood to secrete such inflammatory cytokines as interleukin (IL) 12 and IL18, which then induce sustained microglia activation in the CNS. ${ }^{9}$ Such a shift from adaptive to innate immunity might be critical for the conversion to the progressive phase. We need to study whether the same immunologic changes occur in secondary progressive NMOSD, but given the rarity of such cases, an international collaboration should be launched to address this issue. In the present case of AQP4-IgG-positive NMOSD, the pathologic findings may have a certain resemblance to chronic NMOSD lesions, but the distribution of the brain lesions is not typical of NMOSD and no cerebral cortical abnormalities were described. Further pathologic examination is required for a meticulous comparison of these lesions and the reported pathologic patterns of NMOSD, including loss of AQP4 and perivascular deposition of immunoglobulins and activated complements. ${ }^{10}$ It is also important to examine whether the infiltrating CD68positive macrophages are actively phagocytosing myelin or astrocytic debris, such as glial fibrillary acidic protein, to expand the lesions by a double staining.

Whether alemtuzumab was really involved in the progression in the present case is an open question. Some other disease-modifying drugs for MS (interferon- $\beta$, natalizumab, and fingolimod) can increase the frequency and severity of relapse in AQP4-IgG-positive NMOSD, ${ }^{7}$ but secondary progression has not been reported in those cases. Considering that there are promising candidate drugs for AQP4-IgG-positive NMOSD (including tocilizumab targeting IL6 signaling and eculizumab against complement $\mathrm{C} 5$ ), there will be little reason to justify use of alemtuzumab in this disease in the coming years, but we should definitely elucidate the pathogenetic interaction between innate and adaptive immunity in the chronic progression of NMOSD.

\section{ACKNOWLEDGMENT}

The authors thank Dr. Tatsuro Misu for helpful comments on the neuropathologic findings of the present case.

\section{STUDY FUNDING}

Supported in part by the Grants-in-Aid for Scientific Research (KAKENHI) of The Ministry of Education, Culture, Sports, Science and Technology of Japan, and Health and Labour Sciences Research Grant on Intractable Diseases (Neuroimmunological Diseases) from the Ministry of Health, Labour and Welfare of Japan (K.F.).

\section{DISCLOSURE}

Dr. Fujihara serves on scientific advisory boards for Bayer Schering Pharma, Biogen Idec, Mitsubishi Tanabe Pharma Corporation, Novartis Pharma, Chugai Pharmaceutical, Ono Pharmaceutical, Nihon Pharmaceutical, Merck Serono, and Alexion Pharmaceuticals; has received funding for travel and speaker honoraria from Bayer Schering Pharma, Biogen Idec, Eisai Inc., Mitsubishi Tanabe Pharma Corporation, Novartis Pharma, Astellas Pharma Inc., Takeda Pharmaceutical Company Limited, Asahi Kasei Medical Co., Ltd., and Daiichi Sankyo; serves on the editorial board of Clinical and Experimental Neuroimmunology; and has received research support from Bayer Schering Pharma, Biogen Idec Japan, Asahi Kasei Medical Co., The Chemo-Sero-Therapeutic Research Institute, Teva Pharmaceutical K.K., Mitsubishi Tanabe Pharma Corporation, Teijin Pharma, Eisai Inc., and Kowa Pharmaceuticals America, Inc. and Grants-in-Aid for Scientific Research from the Ministry of Education, Science and Technology and the Ministry of Health, Labor and Welfare of Japan. Dr. Nakashima has received funding for travel and speaker honoraria from Bayer Schering Pharma and Biogen Idec and has received research funding from Mitsubishi Chemical Medicine Corporation and the Grants-in-Aid for Scientific Research from the Ministry of Education, Science and Technology of Japan. Go to Neurology.org/nn for full disclosures.

\section{REFERENCES}

1. Lassmann H, van Horssen J, Mahad D. Progressive multiple sclerosis: pathology and pathogenesis. Nat Rev Neurol 2012;8:647-656.

2. Hauser SL, Chan JR, Oksenberg JR. Multiple sclerosis: prospects and promise. Ann Neurol 2013;74:317-327.

3. Wingerchuk DM, Pittock SJ, Lucchinetti CF, Lennon VA, Weinshenker BG. A secondary progressive clinical course is uncommon in neuromyelitis optica. Neurology 2007;68:603-605.

4. Wingerchuk D, Banwell B, Bennettt J, et al. Revised diagnostic criteria of neuromyelitis optica spectrum disorders. Neurology 2014;82:S63:001.

5. Fujihara K, Misu T, Nakashima I, et al. Neuromyelitis optica should be classified as an astrocytopathic disease rather than a demyelinating disease. Clin Exp Neuroimmunol 2012;3:58-73.

6. Gelfand JM, Cotter J, Klingman J, Huang EJ, Cree BAC. Massive CNS monocytic infiltration at autopsy in an alemtuzumab-treated patient with NMO. Neurol Neuroimmunol Neuroinflamm 2014;1:e34; doi: 10.1212/NXI.0000000000000034. 
7. Kimbrough DJ, Fujihara K, Jacob A, et al. Treatment of neuromyelitis optica: review and recommendations. Mult Scler Relat Disord 2012;1:180-187.

8. Coles AJ, Wing MG, Molyneux P, et al. Monoclonal antibody treatment exposes three mechanisms underlying the clinical course of multiple sclerosis. Ann Neurol 1999;46: 296-304.
9. Weiner HL. A shift from adaptive to innate immunity: a potential mechanism of disease progression in multiple sclerosis. J Neurol 2008;255(suppl 1):3-11.

10. Misu T, Höftberger R, Fujihara K, et al. Presence of six different lesion types suggests diverse mechanisms of tissue injury in neuromyelitis optica. Acta Neuropathol 2013; 125:815-827. 


\title{
Neurology \\ Neuroimmunology \& Neuroinflammation
}

\author{
Secondary progression and innate immunity in NMO: A possible link to alemtuzumab \\ therapy? \\ Kazuo Fujihara and Ichiro Nakashima \\ Neurol Neuroimmunol Neuroinflamm 2014;1; \\ DOI 10.1212/NXI.0000000000000038
}

This information is current as of October 9, 2014

\begin{abstract}
Updated Information \& Services

References

Subspecialty Collections

Permissions \& Licensing

Reprints

including high resolution figures, can be found at:

http://nn.neurology.org/content/1/3/e38.full.html

This article cites 10 articles, 0 of which you can access for free at: http://nn.neurology.org/content/1/3/e38.full.html\#\#ref-list-1

This article, along with others on similar topics, appears in the following collection(s):

Devic's syndrome

http://nn.neurology.org//cgi/collection/devics_syndrome

Multiple sclerosis

http://nn.neurology.org//cgi/collection/multiple_sclerosis

Optic neuritis; see Neuro-ophthalmology/Optic Nerve

http://nn.neurology.org//cgi/collection/optic_neuritis

Transverse myelitis

http://nn.neurology.org//cgi/collection/transverse_myelitis

Information about reproducing this article in parts (figures,tables) or in its entirety can be found online at:

http://nn.neurology.org/misc/about.xhtml\#permissions

Information about ordering reprints can be found online:

http://nn.neurology.org/misc/addir.xhtml\#reprintsus
\end{abstract}

Neurol Neuroimmunol Neuroinflamm is an official journal of the American Academy of Neurology.

Published since April 2014, it is an open-access, online-only, continuous publication journal. Copyright $\odot$ 2014 American Academy of Neurology. All rights reserved. Online ISSN: 2332-7812.

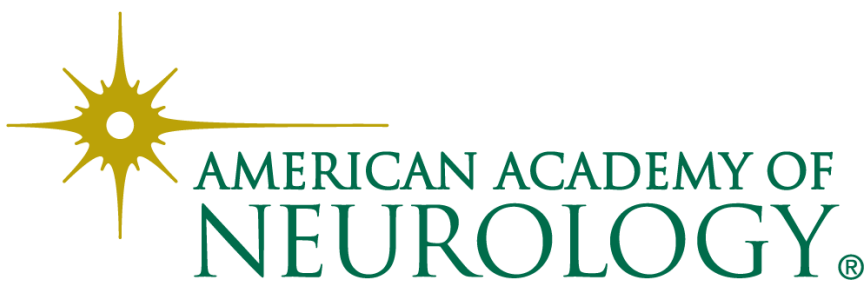

